\title{
Animal Models in Cancer Chemoprevention
}

\section{Khan MA, Singh D and Siddique HR*}

Department of Zoology, Aligarh Muslim University, India

*Corresponding author: Hifzur R Siddique, Molecular Cancer Genetics \& Translational Research Lab Section of Genetics, Department of Zoology, Aligarh Muslim University, Aligarh-202002, India, Tel: +91-9027227104; Email: hifzur.zo@amu.ac.in

\section{Mini Review}

Volume 2 Issue 5

Received Date: August 19, 2019

Published Date: September 16, 2019

DOI: $10.23880 /$ izab-16000171

\section{Abstract}

Animal models are currently being used to check the efficacy of chemo preventive/chemotherapeutic agents. This is because the microenvironment of cultivated primary cells isolated from an animal organ/system is markedly different from in vitro systems. Animal models are important to study the interactions between different cell types and drug/ or xenobiotic metabolisms. To study specific cancer type, animal models can be generated either chemically or trans genetically. A number of tumor-specific animal models are available for chemo preventive studies. To examine the efficacy of chemotherapeutic drugs used for the treatment of various cancers such as prostate, skin, liver, colon etc. are being tested in the different chemically induced or transgenic animal models. However, the validity of animal models in determining the effectiveness of a chemo preventive agent in the human treatment will require the critical evaluation of the positive and negative effects of these agents on human. In this mini-review, we will throw some light on the various small mammalian animal models used in the cancer chemoprevention studies.

Keywords: Animal models; Cancer; Carcinogen; Chemoprevention; Trangenic

Abbreviations: ER: Estrogen Receptor; PI3K: Phosphatidylinositol 3-kinase; PTEN: Phosphatase and Tensin Homolog; 4NQO: 4-Nitroquinoline 1-oxide; HDAC: Histone Deacetylase; NSAID: Non-steroidal antiinflammatory drugs; NNK: 4-(Methyl-nitrosamino)-1-(3pyridyl)-1-butanone Aox: Acyl-CoA Oxidase.

\section{Introduction}

Mammals including humans have very complex physiological functions which are highly integrated and tightly regulated. To study such complex integrative pathways, there is a need to have full description about the mechanisms involved in healthy and diseased conditions. Cultivated primary cells isolated from in vivo systems differ strongly from their corresponding cell types i.e. cultivated cells may have hundreds of genes upregulated or down-regulated in them when they are isolated from their micro-environment. Disadvantages of an in vitro system over in vivo include problems to speculate the chemo-preventive drug concentration/doses, problems to infer the effect of longterm exposure of a drug from in vitro systems, difficulty in checking the interaction between different cell types and difficulty in understanding the xenobiotic metabolism [1].

Till now no in vitro model has fulfilled the criterion to study these complex networks and interactions between signaling molecules in their actual conditions. Animal models display not only genetic similarities but also show similar patterns of genetic alterations. These animal models are used to address the scientific questions from basic science to therapies used for treatment. It should 
also be noted that despite of huge similarities between species, these model organisms have several differences like fine regulation of gene expression, genetic differences which further translate into physiological differences [2]. Animal models are currently being used to testify and to check the efficacy of chemical agents extracted from the natural resources in the treatment of different cancer types. To study the specific form of cancer and its progression, animal models are either established by chemical induction or produced trans-genetically (transgenic animal models). Various animal models are used in the chemoprevention studies as summarized in table 1. For the selection of an ideal Animal model in cancer chemoprevention, the following basis should be followed-

- It should show relevance to human cancer and similar pathology of the cancerous lesion.

- The genetic abnormalities and changes in gene should be similar to those observed in the case of human cancer.

- A consistent tumor burden produced in the animal model should be greater than $60 \%$ within a reasonable time period (less than 6 months) [3].

\begin{tabular}{|c|c|c|c|c|}
\hline Animals & $\begin{array}{c}\text { Chemically } \\
\text { Induced/Transgenic/ } \\
\text { Knock-Out }\end{array}$ & Cancer Type & Characteristics & Reference \\
\hline TRAMP model & Transgenic & Prostate cancer & $\begin{array}{c}\text { PTEN alterationfast growing nature of } \\
\text { cancer }\end{array}$ & {$[3]$} \\
\hline $\begin{array}{c}\text { Sprague Dawley } \\
\text { Female Rat }\end{array}$ & $\begin{array}{c}\text { Methyl Nitrosourea } \\
\text { (MNU) }\end{array}$ & Mammary gland & $\begin{array}{c}\text { Highly sensitive to EGFR and farnesyl } \\
\text { transferase inhibitor. }\end{array}$ & {$[5,6]$} \\
\hline F344 Rats & Azoxymethane (AOM) & $\begin{array}{c}\text { Head and Neck } \\
\text { Cancer }\end{array}$ & $\begin{array}{c}\text { Sensitive to EFGR Inhibitor, HDAC } \\
\text { Inhibitor }\end{array}$ & {$[9]$} \\
\hline $\begin{array}{c}\text { A/J strain of female } \\
\text { mice }\end{array}$ & Benzo[a] pyrene & Lung Cancer & Associated with KRAS mutation & {$[12]$} \\
\hline $\begin{array}{c}\text { Strain A mice } \\
\text { Skh:2 hairless mice }\end{array}$ & Vinyl Carbamate & Lung Cancer & $\begin{array}{c}\text { High multiplicity and production of } \\
\text { carcinoma }\end{array}$ & {$[13]$} \\
\hline $\begin{array}{c}\text { MMTV-Neu/p53KO induced } \\
\text { mice }\end{array}$ & Transgenic & Skin Cancer & $\begin{array}{c}\text { Higher tumor multiplicity p53 mutations } \\
\text { at dipyridine sites sensitive to natural } \\
\text { flavones and various NSAIDS }\end{array}$ & {$[15]$} \\
\hline Mdr-KO mice & Knockout & Liver cancer & $\begin{array}{c}\text { A-catenin negative model CyclinD1 over- } \\
\text { expression }\end{array}$ & {$[18]$} \\
\hline MMTV-PyMT mice & Transgenic & Breast cancer & $\begin{array}{c}\text { Loss of steroid hormone receptor and } \beta 1- \\
\text { integrinErB2 and cyclin D1 over- } \\
\text { expression }\end{array}$ & {$[19]$} \\
\hline Aox-deficient-mouse & Knockout & Liver & $\begin{array}{c}\text { Dys-regulation of gene involved in } \\
\text { involves lipid, carbohydrates and amino } \\
\text { acid metabolism and stress response. }\end{array}$ & {$[20]$} \\
\hline
\end{tabular}

Table 1: Various Animal Models Used In Cancer Chemoprevention Studies.

Limitations of two-dimensional in vitro cancer models are also included while selecting an animal model i.e. selection of phenotypic and genotypic cells, accumulated mutations over a time period, isolation of tumor cells from the tumor microenvironment (TME). Despite successful pre-clinical trials, the chemopreventive drugs that are subjected to trial on these animal models failed largely (only 8\% succeeded to clinical trial) which is likely due to poor methodology and failure to mimic the accurate human diseased conditions [4].

\section{Chemically Induced Rat Models for Cancer Chemoprevention}

Mammary gland carcinogenesis induced by Methyl Nitrosourea (MNU) is an important model to study $\mathrm{ER}^{+}$ cancer in Sprague Dawley female rat. This model shows a high incidence rate of mammary gland carcinogenesis $(>84 \%)$ and development of adenocarcinoma within 120150 days of carcinogen treatment. This model is highly sensitive to EGFR and Farnesyl transferase inhibitor and is also susceptible to hormonal manipulation $[5,6]$. 


\section{International Journal of Zoology and Animal Biology}

To study the chemoprevention drug efficacy, another chemoprevention model for lung cancer has been generated by tobacco-specific carcinogen, NNK in F344 strain of Rats. The majority of animals after NNK treatment displayed lung adenoma and sometimes squamous cell carcinoma after 21 weeks of subcutaneous injection [7]. Sulphur containing compounds like 6-phenyl hexyl isothiocyanate (PHITC), Phenethyl isothiocyanate (PEITC) has shown chemopreventive efficacy in this model [8] 4NQO induced head and neck cancer in rats serves as an effective model for the chemoprevention study. This model is used to study the efficacy of EGFR inhibitor and HDAC inhibitor. Tarceva, which is an EGFR inhibitor, is under human trial.

In colon cancer, cancer induced by azoxymethane (AOM) in F344 rats is an effective model to study the chemopreventive drugs like Aspirin, Cyclooxygenase-2inhibitor, Statin, Ornithine decarboxylase inhibitor and HMG-CoA reductase inhibitor [9].

OH-BBN induced bladder cancer in rats and mice shows similar histopathological changes and invasiveness and similar gene expression changes including Cyclin, Cyclin Kinases, Survivin, Annexin II as in human bladder transitional cell carcinoma (TCC). NSAIDs including Naproxen, Indomethacin and NO-releasing NSAIDs has been reported to show striking effects in this model [3].

3,2'-dimethyl-4-aminobiphenyl (DMAB) induced prostate cancer in F344 rats after 20 weeks subcutaneous injection is an important animal model to study the promoting effects of anti-androgenic agents like 5 alphareductase, Casodex or C17-20 lyase inhibitor [10].

\section{Chemically Induced Mouse Models for Cancer Chemoprevention}

Carcinogen 7, 12 Dimethylbenz[a]anthracene (DMBA) induces $\mathrm{ER} / \mathrm{PR}^{+}$cancer in mouse similar to that in case of human. Long latency turn induced by DMBA displays an $85 \%$ of incidence rate and shows a high frequency of PI3KCa and PTEN mutations [11]. This model is helpful to study agents which are known to modulate cytochrome P450 enzyme system. DMBA is a polycyclic carcinogen which is activated by cytochrome P450 system so it is helpful in studying those chemopreventive agents which target Cytochrome P450 system [3].

In the benzo[a]pyrene model, $\mathrm{A} / \mathrm{J}$ strain of female mice and 16 weeks of treatment displayed $100 \%$ rate of incidence of pulmonary adenomas. In this model, aerosol administration of chemo-preventive drug has an advantage over diet or oral gavage. This carcinogen is associated with KRAS mutation. Budesonide (glucocorticoid) has shown striking effects in this model which led it to clinical trials [12].

Vinyl carbamate carcinogen in 8-9 weeks old treated strain A mice shows high multiplicity and production of carcinoma in a larger proportion, showing more than $30 \%$ of carcinoma lesions. NSAIDs like Piroxicam were used in this type of model to check the efficacy [13].

Compared to other types of cancer, the generation of prostate cancer model is very difficult. MNU/Testosterone treated mice shows a higher rate of cancer incidence and is useful for the chemopreventive study of anti-androgen, Prasterone etc. [14].

UV induced skin cancer in Skh:2 hairless mice is also an effective model to study the chemopreventive role of natural flavones and various NSAIDS like Celecoxib, Piroxicam etc. This model shows a $100 \%$ incidence rate of cancer after UV-exposure and has a higher tumor multiplicity [15].

Liver cancer induced in mice by diethylnitrosamine and Phenobarbital which shows $100 \%$ hepatoma is recently being used as a model for the therapeutic drug treatment studies of liver cancer. Bicyclol which is an anti-hepatitis drug has been shown to inhibit the malignant transformation of liver cancer in this model [16].

\section{Transgenic/ Knock-Out Models For Cancer Chemoprevention}

MMTV-Neu/p53KO transgenic mice have EGFR (Neu) expression under the control of MMTV promoter and also have a heterozygous knockout of p53. This model resembles around $20-25 \%$ of human cancers having p53 mutation. EGFR inhibitor, RXR agonist like Bexarotene and UAB-30 are showing high susceptibility to this model [17].

The transgenic mouse prostate (TRAMP) model, where PTEN alteration is present shows chemopreventive susceptibility to the drug such as Toremifen. This model has an advantage to study the human prostate cancer because of its fast-growing nature and thus making it an important model for the effective drug study [3].

Mdr2 Knockout mice (Mdr-KO) is a transgenic model used to study hepatocellular carcinoma (HCC). This model shows several dysregulated pathways and gene 


\section{International Journal of Zoology and Animal Biology}

expression as in human HCC. It serves as a $\beta$-catenin negative model and shows CyclinD1 over-expression. Selenium and anti-oxidant agents have shown efficacy to this model [18].

MMTV-PyMT transgenic mouse model is an important model used to study breast cancer metastasis. This model shows a gradual loss of steroid hormone receptor and $\beta 1$ integrin. In late metastatic stage, it shows overexpression of ErB2 and Cyclin D1 which has close similarities with human breast cancer. Dipyridamole (DPM) shows potential chemopreventive effects in this model [19].

Aox-deficient-mouse is another model used to study the pathogenesis of liver cancer and the contribution of peroxisome receptors. The dysregulated genes in this model are those which involves lipid, carbohydrates, amino acid metabolism and stress response. This model is important to understand the correlation between hepatic metabolic functions and formation of tumor [20].

\section{Conclusion}

A number of animal models are used to determine the efficacy of a chemo preventive agent. Based on the preclinical studies using animal models; the effective dose, xenobiotic study and toxicity of the chemo preventive agents are tested in real-time. However there is a lot of scope and need of improvement in the existing animal models in order to give a precise reflection of the process of the progression of the various cancers. Further, there is a need for the development of animal models for the determination of the efficacy of chemo preventive agents in the treatment of cancers of other organs such as brain, cervix, hematopoietic system etc. The use of animal models in determining the efficacy of a chemotherapeutic drug further requires the data from human trial which will represent the pros and cons of using the chemotherapeutic agent in human. All this remains centralized to the clinical trial process. Our lab is currently working on testing the efficacy of various chemotherapeutic drugs in the liver, oral, skin and prostate cancer using established animal models.

\section{Acknowledgment}

The authors are thankful to the Department of Zoology, AMU, Aligarh for providing necessary laboratory facilities. MAK and DS express their sincere gratitude to CSIR and UGC, India for Fellowships respectively. HRS is thankful to the UGC [Grant no. F.30-377/2017(BSR)] and DST-SERB (Grant no. EMR/2017/001758), New Delhi, for providing financial help. We also apologize to eminent researchers working in this field whose work could not be cited in the review due to limitations of space.

\section{References}

1. Ghallab A (2013) In vitro test systems and their limitations. EXCLI J 12: 1024-1026.

2. Barré Sinoussi F, Montagutelli X (2015) Animal models are essential to biological research: issues and perspectives. Future Sci OA 1(4): FSO63.

3. Steele VE, Lubet RA (2010) The use of animal models for cancer chemoprevention drug development. Sem in Oncol 37(4): 327-338.

4. Mak IW, Evaniew N, Ghert M (2014) Lost in translation: animal models and clinical trials in cancer treatment. Am J Transl Res 6(2): 114-118.

5. Baum M, Budzar AU, Cuzick J, Forbes J, Houghton JH, et al. (2002) Anastrozole alone or in combination with tamoxifen versus tamoxifen alone for adjuvant treatment of postmenopausal women with early breast cancer: first results of the ATAC randomised trial. Lancet 359(9324): 2131-2139.

6. Russo J, Yang X, Hu YF, Bove BA, Huang Y, et al. (1998) Biological and molecular basis of human breast cancer. Front Biosci 3: D944-960.

7. Hecht SS, Chen CB, Ohmori T, Hoffman D (1980) Comparative Carcinogenicity in F344 Rats of the Tobacco-specific Nitrosamines, $\mathrm{N}^{\prime}$-Nitrosonornicotine and 4-(N-Methyl-N-Nitrosamino)-1-(3-pyridyl)-1butanone.Can Res 40(2): 298-302.

8. Chung FL, Kelloff G, Steele V, Pittman B, Zang E, et al. (1996) Chemopreventive efficacy of arylalkyl isothiocyanates and $\mathrm{N}$-acetylcysteine for lung tumorigenesis in Fischer rats. Cancer Res 56(4): 772728.

9. Reddy BS, Wang CX, Kong AN, Khor TO, Zheng X, et al. (2006) Prevention of azoxymethane-induced colon cancer by combination of low doses of atorvastatin, aspirin, and celecoxib in F 344 rats. Cancer 66(8): $4542-4526$.

10. Akaza H, Tsukamoto S, Morita T, Yamauchi A, Onozawa M, et al. (2000) Promoting effects of anti androgenic agents on rat ventral prostate carcinogenesis induced by 3,2'-dimethyl-4- 


\section{International Journal of Zoology and Animal Biology}

aminobiphenyl (DMAB). Prostate Cancer Prostatic Dis 3(2): 115-119.

11. Abba MC, Zhong Y, Lee J, Kil H, Lu Y, et al. (2016) DMBA induced mouse mammary tumors display high incidence of activating Pik3caH1047 and loss of function Pten mutations. Oncotarget 7(39): 64289. 64299.

12. Wattenberg LW, Wiedmann TS, Estensen RD, Zimmerman CL, Steele VE, et al. (1997) Chemoprevention of pulmonary carcinogenesis by aerosolized budesonide in female A/J mice. Cancer Res 57(24): 5489-5492.

13. Gunning WT, Kramer PM, Lubet RA, Steele VE, Pereira MA (2000) Chemoprevention of vinyl carbamateinduced lung tumors in strain A mice. Exp Lung Res 26(8): 757-772.

14. Bosland MC, Prinsen MK, Kroes R (1983) Adenocarcinomas of the prostate induced by $\mathrm{N}$ nitroso-N-methylurea in rats pretreated with cyproterone acetate and testosterone. Cancer Lett 18(1): 69-78.

15. Fischer SM, Lo HH, Gordon GB, Seibert K, Kelloff G, et al. (1999) Chemopreventive activity of celecoxib, a specific cyclooxygenase-2 inhibitor, and indomethacin against ultraviolet light-induced skin carcinogenesis. Mol Carcinog 25(4): 231-240.
16. Sun H, Yu L, Wei H, Liu G (2012) A novel antihepatitis drug, bicyclol, prevents liver carcinogenesis in diethylnitrosamine-initiated and phenobarbitalpromoted mice tumor model. J Biomed Biotechnol 2012: 584728.

17. Lubet RA, Steele VE, Shoemaker RH, Grubbs CJ (2018) Screening of Chemopreventive Agents in Animal Models: Results on Reproducibility, Agents of a Given Class, and Agents Tested During Tumor Progression. Cancer Prev Res (Phila) 11(10): 595606.

18. Katzenellenbogen M, Mizrahi L, Pappo O, Klopstock N, Olam D, et al. (2007) Molecular mechanisms of the chemopreventive effect on hepatocellular carcinoma development in Mdr2 knockout mice. Mol Cancer Ther 6(4): 1283-1291.

19. Wang C, Schwab LP, Fan M, Seagroves TN, Buolamwini JK (2013) Chemoprevention activity of dipyridamole in the MMTV-PyMT transgenic mouse model of breast cancer. Cancer Prev Res 6(5): 437447.

20. Bakiri L, Wagner EF (2013) Mouse models for liver cancer. Mol Oncol 7(2): 206-223. 